\title{
Physical Properties of Cement System Insulation Using Blast Furnace Slag
}

\author{
Sung Kwan Seo, Jae Wan Park, Hyeong Kyu Cho, and Yong Sik Chu ${ }^{\dagger}$ \\ Energy and Environmental Division, Korea Institute of Ceramic Engineering and Technology, Jinju 52851, Korea
}

(Received November 1, 2017; Revised November 23, 2017; Accepted December 11, 2017)

\begin{abstract}
In this study, fabrication method of inorganic insulation were studied to reduce $\mathrm{CO}_{2}$ from buildings. Main materials for inorganic insulation were used cement, blast furnace slag and aluminum powder as foaming agent. Mixing ratio of cement and slag was controlled and physical properties of inorganic insulation were analyzed. When inorganic insulation was fabricated using cement and slag, expanded slurries were not sunken and hardened normally. Pore size was 0.5 - $2 \mathrm{~mm}$; mean pore size was about $1 \mathrm{~mm}$ in inorganic insulation. Compressive strength of inorganic insulation increased with curing time and increased slightly with cement fineness. However, specific gravity decreased slightly with curing time; this phenomenon was caused by evaporation of adsorptive water. When inorganic insulation was dried at $60^{\circ} \mathrm{C}$, compressive strength was higher than that of undried insulation. The highest compressive strength was found with a mixture of cement (50\%) and slag (30\%) in inorganic insulation. Compressive strength was $0.32 \mathrm{MPa}$, thermal conductivity was $0.043 \mathrm{~W} / \mathrm{mK}$ and specific gravity was $0.12 \mathrm{~g} / \mathrm{cm}^{3}$.
\end{abstract}

Key words : Inorganic insulation, Cement, Slag, Compressive strength, Thermal conductivity

\section{Introduction}

$\mathrm{G}$ reenhouse gas emission from buildings accounts for Tabout $25 \%$ of the total emission in South Korea. Since the energy consumption at buildings will further increase due to economic growth, the ratio of the greenhouse gas emission from buildings is expected to grow to about $40 \%{ }^{1,2)}$ Accordingly, various methods of reducing energy consumption at buildings have been conducted in South Korea. ${ }^{3-5}$ ) Highly efficient and environment-friendly insulation materials have been developed in many countries, and the competitiveness of insulation materials is considered as a reference of national energy utilization efficiency. In advanced countries, such as European countries and Japan, national standards for insulation materials have been amended, and problems of insulation materials (strength, economic feasibility, fire resistance, buildability, human body hazard, etc.) have been overcome. ${ }^{6)}$

Insulation materials may be classified as organic and inorganic materials; the organic insulation materials include Styrofoam and polyurethane. These materials have excellent thermal insulation properties and are available at a low cost, but may result in large fires and generate hazardous gases in the case of a fire. ${ }^{7,8)}$

Inorganic insulation materials, such as glass fiber and rock wool, are non-combustible materials that are safe in the case of a fire, but may experience a decrease of insula-

\footnotetext{
Corresponding author: Yong Sik Chu

E-mail : yschu@kicet.re.kr

Tel : +82-55-792-2463 Fax : +82-55-792-2469
}

tion and exacerbation of durability when the materials absorb water. To solve these problems, a novel inorganic insulation material for which the water absorption may be controlled needs to be developed. In Germany and other countries, insulation materials having controllable water absorptivity and that are safe against fire are already in use. These materials are inorganic insulation materials manufactured by hydrothermal synthesis at $180^{\circ} \mathrm{C}$. A representative example of these materials is Multipor ${ }^{\mathbb{B}}$ (Xella), manufactured using cement, lime, and silica powder as raw powder materials and aluminum powder as a foaming agent. ${ }^{9)}$ In hydrothermal synthesis-based manufacturing, these raw materials are mixed with water for foaming. In European countries, a method of using high-fineness cement and a vegetable foaming agent has been studied, but the method has not been completed. ${ }^{10)}$ The room temperaturebased method does not require a heat source, but method development is still at the level of fundamental theory because of the poor foaming performance and physical properties. Therefore, systematic research and development work should be carried out continuously to develop a room temperature-based method for manufacturing inorganic insulation materials.

The present study was conducted to develop a room temperature-based method for manufacturing inorganic insulation materials without a heat source. The raw powder materials used were cement and slag; the foaming agent used was an aluminum-based foaming agent. The content of the cement and slag was varied, and the physical properties of the resulting material were analyzed depending on the cement and slag content. 


\section{Experimental Procedure}

A fine slag powder was used to prepare a cement-based inorganic insulation material, because such a powder may effectively show strength at an old material age and provide initial slurry stability (prevention of slurry collapse).

Commercially available ordinary Portland cement (OPC, S Company) was pulverized using a vibration mill, controlling the fineness at 7,500 and $10,000 \mathrm{~cm}^{2} / \mathrm{g}$. A fine powder of commercially available slag was obtained and pulverized to a fineness of $7,000 \mathrm{~cm}^{2} / \mathrm{g}$. The lime used in the present study was purchased from B Company; anhydrite was from J Company. Table 1 shows the mixing ratios of the cement and slag for the investigation of the properties of the resulting inorganic insulation material. The slag content was varied at $10 \%, 15 \%, 20 \%, 25 \%, 30 \%$, and $35 \%$; the cement content was varied from $45 \%$ to $70 \%$. The content of the lime was fixed at $10 \%$ and that of the anhydrite was either $5 \%$ or $10 \%$. The ratio of SMK 1311 , a chemical admixture for removing gigantic foams and securing foam stability, was fixed at $0.06 \%$, and the content of a silicone-based water-repellent was fixed at $0.1 \%$. The content of the aluminum powder foaming agent was also fixed at $0.6 \%$.

To prepare the primary slurry, powders of OPC, slag, lime, and anhydrite were mixed together. Then, water was mixed in at a ratio of $130 \%$ of the binder weight and SMK 1311 was added to prepare the slurry. The mold for the for- mulation of the slurry was a Styrofoam mold of dimensions $220 \times 220 \times 220 \mathrm{~mm}$.

The aluminum powder was added to the slurry and the resulting mixture was sufficiently mixed to prepare the final slurry, which was then kept in the air. After about two hours, the slurry expanded to a maximum volume because the reaction between the aluminum powder and the hydrates to produce hydrogen gas was completed within about two hours. Fig. 1 is an image of the final slurry after the foaming was completed. The prepared specimens were removed from the mold $24 \mathrm{~h}$ after the preparation of the primary slurry. The specimens removed from the mold were cured at the indoor temperature of $25 \pm 2^{\circ} \mathrm{C}$ and a relative humidity over $60 \%$. The curing period was fixed at $3,7,15$, and 28 days. After each of the curing periods had passed, the density, compressive strength, and thermal conductivity of the specimens were measured, and the pores in the specimens were also observed.

\section{Results and Discussion}

\subsection{Slurry Preparation Properties}

As shown in Fig. 1, all the slag-mixed slurry specimens showed good foaming without slurry setting or collapse (backing, etc.). The internal temperature of all the samples of foaming slurry was below $45^{\circ} \mathrm{C}$, but slightly increased as the slag content was increased. However, no correlation

Table 1. Mixing Ratios of Slurry for Thermal Insulation

(Unit : \%)

\begin{tabular}{|c|c|c|c|c|c|c|c|c|c|}
\hline \multirow{2}{*}{ No. } & \multicolumn{2}{|c|}{$\overline{\mathrm{OPC}}$} & \multirow{2}{*}{ Slag } & \multirow{2}{*}{ Lime } & \multirow{2}{*}{ Anhydrite } & \multirow{2}{*}{ Water } & \multirow{2}{*}{ SMK 1311} & \multirow{2}{*}{$\begin{array}{c}\text { Water } \\
\text { Repelling Agent }\end{array}$} & \multirow{2}{*}{ Al Powder } \\
\hline & 10,000 & 7,500 & & & & & & & \\
\hline 1 & 50 & - & 35 & 10 & 5 & 130 & 0.06 & 0.1 & 0.6 \\
\hline 2 & 50 & - & 30 & 10 & 10 & 130 & 0.06 & 0.1 & 0.6 \\
\hline 3 & - & 45 & 35 & 10 & 10 & 130 & 0.06 & 0.1 & 0.6 \\
\hline 4 & - & 50 & 30 & 10 & 10 & 130 & 0.06 & 0.1 & 0.6 \\
\hline 5 & - & 55 & 25 & 10 & 10 & 130 & 0.06 & 0.1 & 0.6 \\
\hline 6 & - & 60 & 20 & 10 & 10 & 130 & 0.06 & 0.1 & 0.6 \\
\hline 7 & - & 65 & 15 & 10 & 10 & 130 & 0.06 & 0.1 & 0.6 \\
\hline 8 & - & 70 & 10 & 10 & 10 & 130 & 0.06 & 0.1 & 0.6 \\
\hline
\end{tabular}
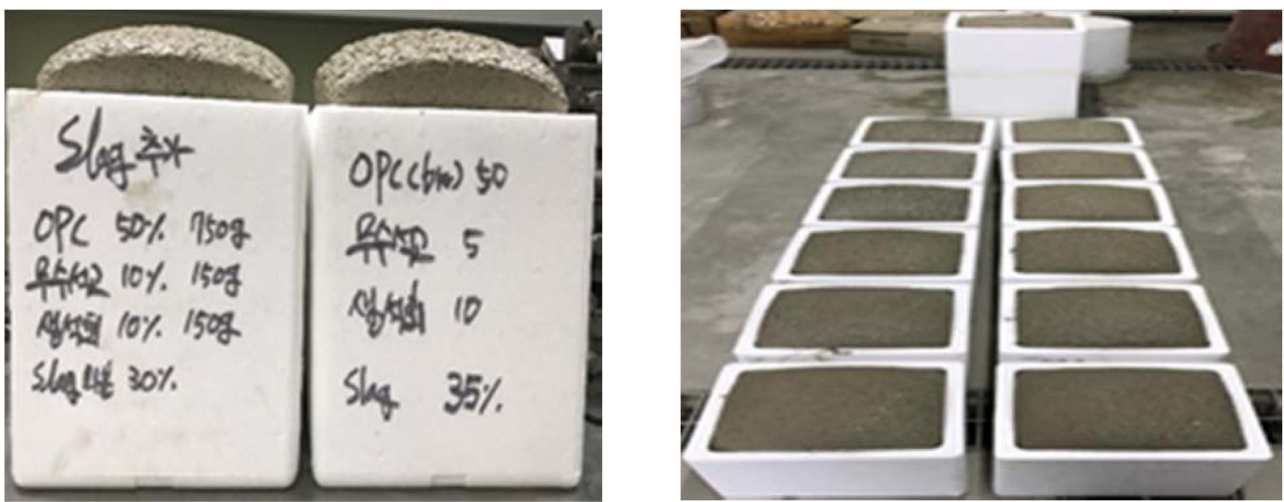

Fig. 1. Hardened slurries according to mixing ratios after $24 \mathrm{~h}$. 


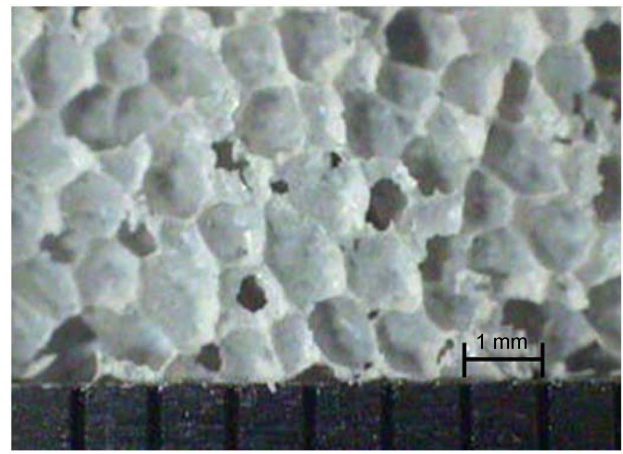

(a) No.2

Fig. 2. Pore structure of hardened slurry after $24 \mathrm{~h}$.

between the internal slurry temperature and the slag content was clearly derived. That the foaming slurry showed neither cracking in the cured slurry, nor collapse, even after $24 \mathrm{~h}$, indicated that the cured slurry remained very stable even after $24 \mathrm{~h}$.

Figure 2 shows the pores in the Nos. 2 and 4 slurry specimens after $24 \mathrm{~h}$ of curing. The size of the pores in the Nos. 2 and 4 slurry specimens was in a range from about 0.5 to 2 $\mathrm{mm}$; the average pore size was about $1 \mathrm{~mm}$. Some of the pores were connected pores and open pores, while others were closed pores. The close pores may have a positive effect on the insulation performance; they may also contribute to an increase of the compressive strength. ${ }^{11)}$

\subsection{Physical Properties Depending on Number of Curing Days}

As described above, the density, compressive strength, and thermal conductivity of the cured slurry specimens were measured after curing for 3, 7, 15, and 28 days. The prepared specimens were cured during each of the curing periods at a temperature of $25 \pm 2^{\circ} \mathrm{C}$ and a relatively humidity of over $60 \%$. Fig. 3 shows the appearance of the specimens after 15 days of curing. All the specimens were in a good condition without cracks.

Figure 4 shows the density of the specimens depending on the curing period. As the curing period was increased, the density decreased. In particular, the density greatly decreased

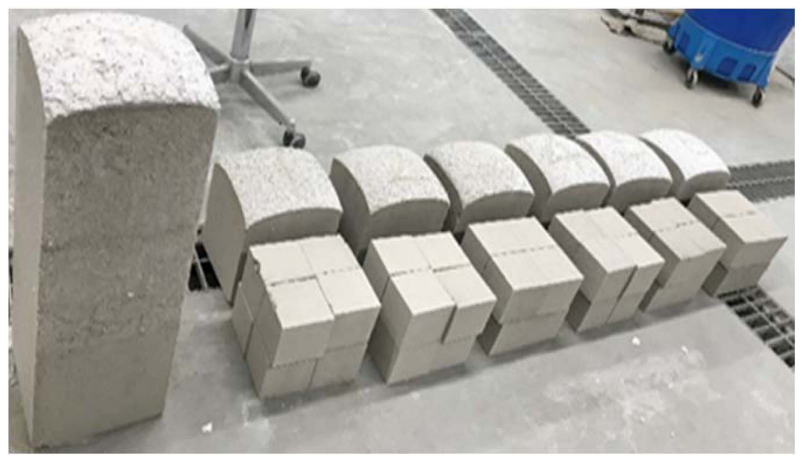

Fig. 3. Apparent conditions of specimens after 15 days.

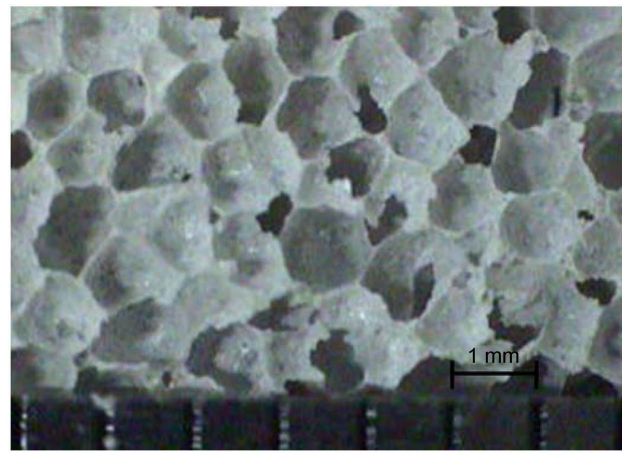

(b) No.4

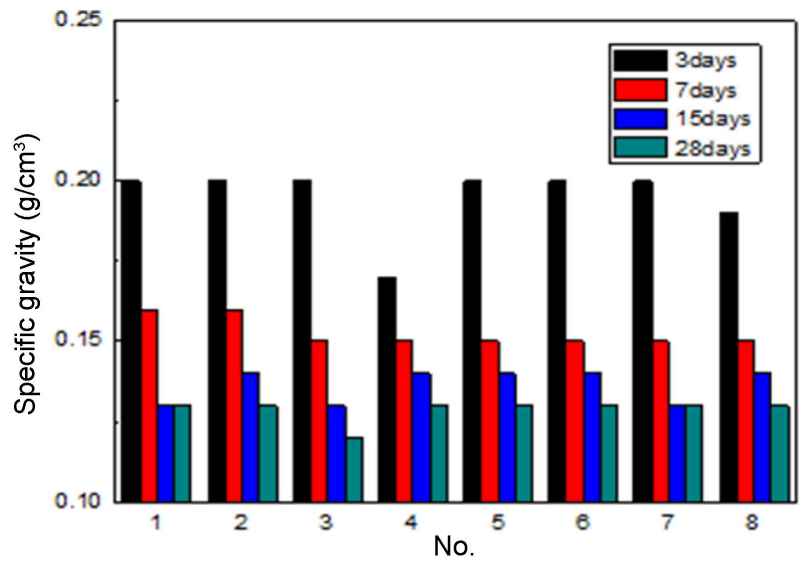

Fig. 4. Specific gravity with curing time.

from the material age of 3 days to 7 days. The density slightly decreased when the curing period was increased from 14 days to 28 days. The density was not affected by the slag mixing conditions, while the density was strongly affected by the curing period. This may be because the water included in the cured slurry specimens may have been evaporated more rapidly in the earlier stage of curing.

Figure 5 shows the variation of the compressive strength depending on the cement fineness and the curing period.

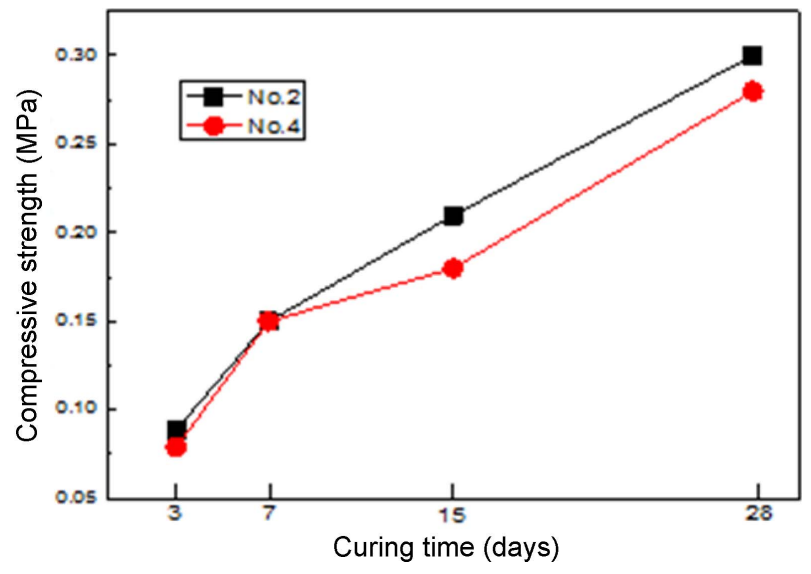

Fig. 5. Compressive strength with cement fineness. 
The compressive strength generally increased with the increase of the curing period and the OPC fineness. Comparing the No. 2 and 4 specimens, having respective fineness values of $10,000 \mathrm{~cm}^{2} / \mathrm{g}$ and $7,500 \mathrm{~cm}^{2} / \mathrm{g}$, the compressive strength of the No. 2 specimen was slightly higher, indicating that the compressive strength slightly increased with the increase of the cement fineness (The compressive strength values of the No. 2 and 4 specimens after the material age of 28 days were $0.3 \mathrm{MPa}$ and $0.28 \mathrm{MPa}$, respectively). Since the porosity was about $90 \%$ and the volume occupied by the matrix was as little as about $10 \%$, the contribution of the matrix was very small, and thus the compressive strength was not significantly dependent on the matrix fineness.

Figure 6 shows the compressive strength depending on the mixing ratios shown in Table 1 . As can be seen in Fig. 6 , the compressive strength increased with the increase of the curing period. The highest compressive strength values were found at a slag content of $30 \%$ (cement content $50 \%$ ) after 15 days and 28 days of curing period. As the curing period was further increased, the compressive strength gradually decreased as the slag content was decreased and the cement content was increased. The decrease of the compressive strength was caused by both the decrease of the slag content and the increase of the cement content. Generally, when a slag is used, the Pozzolanic reaction occurs, improving the strength. The Pozzolanic reaction is generally known to be enhanced as the curing period increases. However, this is true only when an appropriate amount of slag is used, and thus the Pozzolanic reaction may be dependent on the properties of the specimens and the curing conditions. As shown in Fig. 6(a), the difference of the compressive strength between the specimens was more after 28 days of curing than after 3 days and 7 days of curing. This may be because of the appropriate slag content condition and the difference of the Pozzolanic reactivity. ${ }^{12)}$ Hence, considering the Pozzolanic reactivity, the optimal mixing ratio may be slag $30 \%$ and cement $50 \%$. Fig. 6(b) shows the compressive strength data for only a curing period of 28 days, more specifically indicating the gradual decrease of the compressive

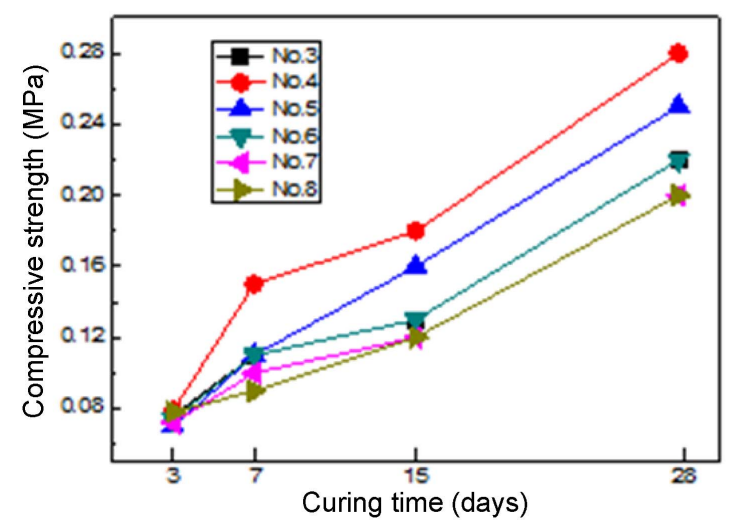

(a) $3 \sim 28$ days strength after the peak of the No. 4 specimen mixing condition.

\subsection{Physical Properties of Dried Specimens}

After completing each of the curing periods, the specimens prepared according to the method described in Section 3.2 were dried and their physical properties were analyzed. The specimens were dried by increasing the temperature by $10^{\circ} \mathrm{C}$ per hour from $30^{\circ} \mathrm{C}$ to $60^{\circ} \mathrm{C}$. Then, to minimize heat shock to the specimens, the specimens were sufficiently dried at $60^{\circ} \mathrm{C}$ until the weight became constant. No cracks due to heat shock were found on the specimens after drying. The compressive strength, over-dried density, and thermal conductivity were measured after the drying to review the possibility of using the material as an insulation material.

Figure 7 shows the over-dried density of the specimens. The over-dried density of the specimens was not dependent on the mixing ratios. The density values of all the dried specimens were similar, in a range of 0.11 to $0.12 \mathrm{~g} / \mathrm{cm}^{3}$. Fig. 8 shows the compressive strength of the dried specimens. The compressive strength increased with the increase of the curing period. The compressive strength of some specimens was higher than 0.3 $\mathrm{MPa}$ after 28 days of curing. The compressive strength of the dried specimens was slightly higher

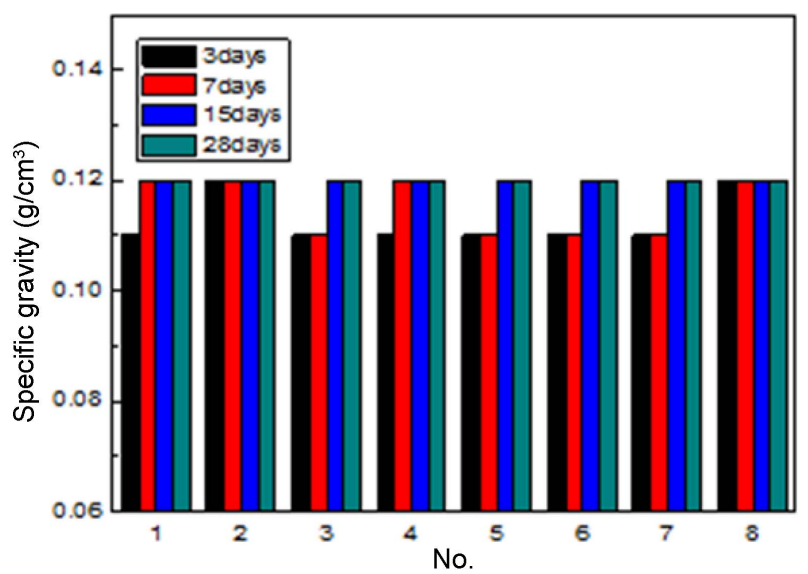

Fig. 7. Specific gravity of dried specimen at $60^{\circ} \mathrm{C}$.

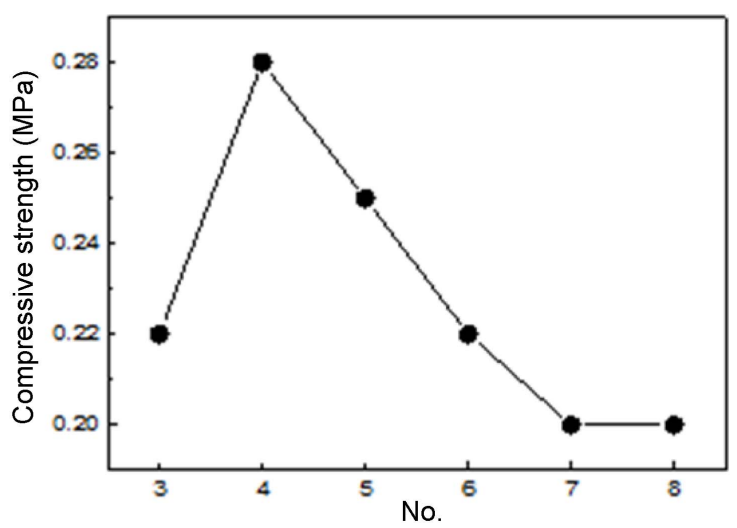

(b) 28 days

Fig. 6. Compressive strength with mixing ratios. 


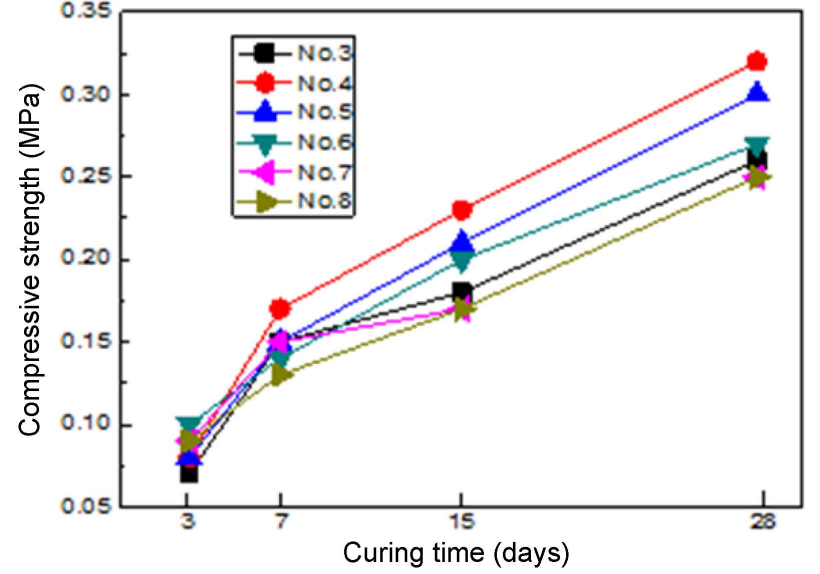

Fig. 8. Compressive strength of dried specimen at $60^{\circ} \mathrm{C}$.

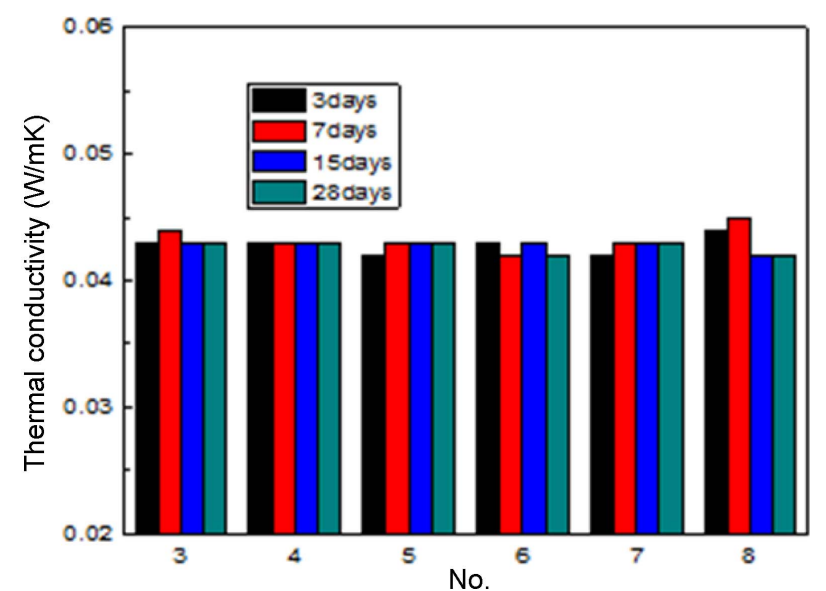

Fig. 9. Thermal conductivity of dried specimen at $60^{\circ} \mathrm{C}$.

than that of the specimens before drying, indicating that the hydration reaction between the slag and the cement occurred more during the drying process. However, the compressive strength values of each specimen were not different before and after drying. The thermal conductivity of the dried specimens was dependent on neither the curing period nor on the mixing ratio (Fig. 9).

The thermal conductivity of all specimens was in the range of 0.041 to $0.043 \mathrm{~W} / \mathrm{mK}$ for all the curing periods. In addition, the thermal conductivity values of the No. 3 and 5 specimens were similar at $0.043 \mathrm{~W} / \mathrm{mK}$. This shows that the thermal conductivity is not dependent on the hydration reaction between the cement and the slag, but on the pore properties (pore volume and pore type, etc.). Fig. 10 shows the pore characteristics of the No. 4 specimen after drying, as analyzed using an image analyzer (IA). The blue region represents the pores, while the gray region represents the matrix. The image shows that many pores were included in the specimen. The porosity analyzed by the IA was $90.0 \%$, and the average pore size was $0.84 \mathrm{~mm}$. The pore characteristics are consistent with the pore characteristics observed

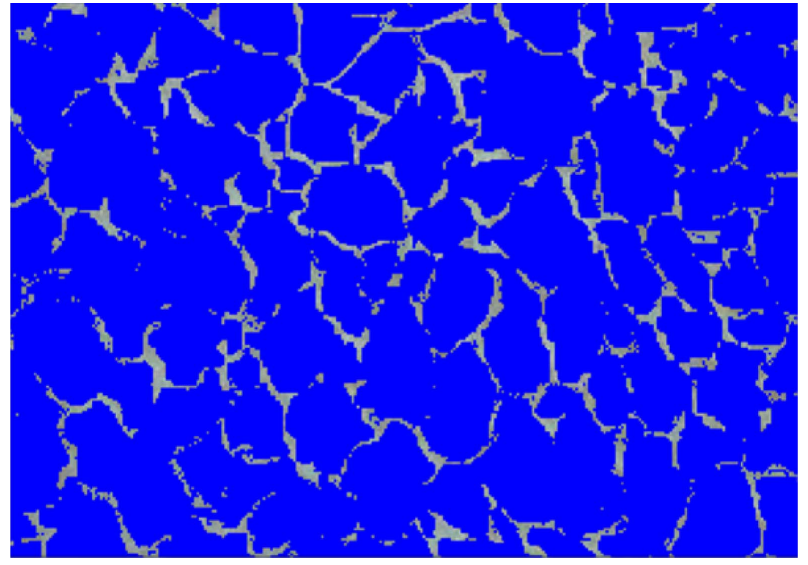

Fig. 10. Pore characteristics of No.4, obtained by image analyzer.

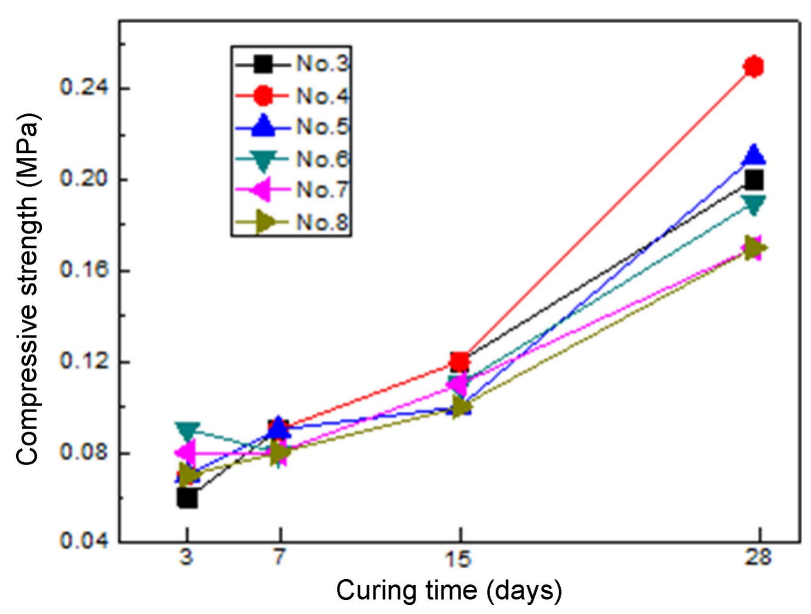

Fig. 11. Compressive Strength of dried specimen at $80^{\circ} \mathrm{C}$.

in the slurry cured for $24 \mathrm{~h}$, as shown in Fig. 2. The experimental results verified that the compressive strength was dependent on the drying temperature. Therefore, the drying temperature was increased from $60^{\circ} \mathrm{C}$ and $80^{\circ} \mathrm{C}$. The dryer temperature was increased at a rate of $10^{\circ} \mathrm{C}$ per hour, and kept at $80^{\circ} \mathrm{C}$ until the weight became constant. Fig. 11 shows the compressive strength after drying at $80^{\circ} \mathrm{C}$.

With the drying temperature of $80^{\circ} \mathrm{C}$, the compressive strength did not increase but decreased. After 28 days of curing, the maximum compressive strength was $0.25 \mathrm{MPa}$, and the minimum compressive strength was $0.17 \mathrm{MPa}$, indicating that the compressive strength decreased slightly after drying. The decrease of the compressive strength after drying at $80^{\circ} \mathrm{C}$ may be because of crack generation due to heat shock during drying. The heat shock might have caused thermal degradation of hydrates, such as ettringite, a cement hydrate, as well as shrinkage of the specimen. Therefore, the drying temperature necessary to acquire the maximum compressive strength may be $60^{\circ} \mathrm{C}$. 


\section{Conclusions}

In the present study, an inorganic insulation material was prepared at room temperature using cement, lime, and silica powder as raw powder materials, and aluminum powder as a foaming agent. The contents of cement and slag were varied, and the physical properties of the resulting material were analyzed depending on the cement and slag content. The following conclusions were obtained from the present study.

1. When the insulation material was prepared using cement and slag, the foaming slurry was normally cured without setting. The sizes of the pores in the insulation material were about 0.5 to $2 \mathrm{~mm}$, and the average pore size was about $1 \mathrm{~mm}$.

2. The compressive strength of the insulation material generally increased with the increase of the curing period. The compressive strength of the insulation material also slightly increased with the increase of the cement fineness. On the other hand, the density gradually decreased as the curing period increased, which may be because the water included in the material evaporated.

3. At the drying temperature of $60^{\circ} \mathrm{C}$, the compressive strength increased after drying. The highest compressive strength was found under the mixing condition of slag $30 \%$ and cement $50 \%$. Under that condition, the compressive strength was $0.32 \mathrm{MPa}$, the thermal conductivity was 0.043 $\mathrm{W} / \mathrm{mK}$, and the over-dried density was $0.12 \mathrm{~g} / \mathrm{cm}^{3}$. However, as the drying temperature was increased to $80^{\circ} \mathrm{C}$, the compressive strength decreased, which may be because the hydrates existing in the insulation material had been thermally degraded.

The present study showed that an inorganic insulation material may be successfully prepared at room temperature by appropriately mixing slag and cement. In addition, the inorganic insulation material prepared at room temperature showed proper compressive strength and thermal conductivity, indicating that the material may be applied to buildings.

\section{REFERENCES}

1. Y. S. Song, W. Y. Jeong, and T. H. Kim, "An Examination of Application Plan of Proper CDM for GHG Reduction," J. Reg. Assoc. Archit. Inst. Korea, 12 [4] 82-177 (2010).

2. Y. S. Jeong and H. K. Jung, "A Study on Calculation Method for the Gas Emission of Building Sector," J. Reg. Assoc. Archit. Inst. Korea, 37 [1] 499-500 (2017).

3. S. K. Jeong, J. S. Jeon, and J. K. Seo, "Consideration for application of Phase Change Material for Building Energy Saving," J. KIAEBS, 5 [1] 1-9 (2011).

4. K. H. Lee and C. W. Chae, "A Study on the Amount of the Energy Consumption and $\mathrm{CO}_{2}$ Emission of Public Building using the Input-Output Analysis," Architectural Institute of Korea, 18 [5] 99-107 (2002).

5. J. H. Park and T. H. Hoon, "Improvements of Policies Related Building Energy Reduction in Korea," Korea Inst. Construct. Eng. Manage., 11 [4] 14-21 (2010).

6. J. M. Park, D. H. Kim, and D. J. Suh, "Recent Research Trends for Green Building Thermal Insulation Materials," Clean Technol., 18 [1] 14-21 (2012).

7. D. K. Kim and S. B. Lee, "Properties and Thermal Characteristics of Phenol Foam for Heat Insulating Materials," J. Ind. Eng. Chem., 17 [4] 357- 60 (2006).

8. J. S. Roh, J. Y. Yoon, K. J. Moon, Y. K. Cho, and Y. S. So, "Heating Value and Noxious Gases Generation of Sandwich Panel Core Using Artificial Lightweight Aggregate"; pp. 261-66 in Proceedings of Korea Concrete Institute, 2003.

9. J. S. Kim, "Efficient Application of Insulation for Green Plant," Korean J. Chem. Eng., 29 [1] 79-84 (2011).

10. M. S. Ahn, T. K. Park, I. S. Hwang, and B. I. Kim, "Effect of Gypsum and Cement on Hydrothermal Reaction in Fly Ash-Lime System," J. Korean Ceram. Soc., 35 [10] 103039 (1998).

11. J. K. Park and J. S. Lee, "Preparation of Porous Inorganic Materials by Foaming Slurry," J. Korean Ceram. Soc., 35 [1] 1280-85 (1998).

12. W. K. Jung, K. H. Kim, B. J. Jeon, and J. O. Bae, "Development of Carbon Reduction Concrete Using The Pozzolan Reaction Cement"; pp. 77-8 in Proceedings of Korea Concrete Institute, 2013. 